\title{
DESIGN OF HARDWARE-IN-THE-LOOP TEST BENCH FOR BRAKING AND ANTI-SKID OF TRAINS
}

\author{
JIAJUN ZHOU \& MENGLING WU \\ Institute of Rail Transit, Tongji University, China
}

\begin{abstract}
To meet the needs of train braking and anti-skid simulation, a hardware-in-the-loop test bed based on the co-simulation model of LabVIEW and AMESim was designed. The hardware of the test bench is mainly composed of an industrial personal computer (IPC), the data acquisition cards and the frame control braking devices (excluding the pneumatic valve unit). IPC provides virtual train vehicle, virtual train running environment, virtual electric brake unit and virtual pneumatic valve unit. In the form of a hardware-in-the-loop test bench, it realizes the functions of train traction, braking and anti-skid. Finally, according to the requirements of standard EN 15595, the validation of the test-bed is verified by comparing the actual line data with the simulation data.
\end{abstract}

Keywords: braking, anti-skid, hardware-in-the-loop, validation of test bench.

\section{INTRODUCTION}

At present, there are two ways to test the performance of train braking and anti-skid system. One is the real line test. The train equipped with the braking system is pulled onto the test line. By spraying antifriction fluid on the rail surface, the adhesion of the rail surface is deteriorated, and then the antiskid test is carried out. The other is the bench test. Based on numerical simulation of wheel-rail adhesion, vehicle dynamics and other related theories, combined with hardware-in-the-loop simulation method to build a semi-physical simulation test bench, the braking and anti-skid system test are carried out on the bench. Compared with the former, the latter bench simulation test cannot be completely compared in the authenticity and reliability of test results. However, it has the advantages of low cost, less time-consuming, high safety factor, low management difficulty and strong operability, which can greatly improve the research efficiency, save the development cycle and cost of braking system.

Many researchers have established a simulation test bench of braking and anti-skid system by means of hardware in the loop. Trenitalia spa, an Italian railway company, has designed the MI-6 multi-functional hardware in the loop test bench for rail vehicles [1]-[3]. It has a variety of railway safety related electronic system testing capabilities, such as ATP, WSP, etc. The German DB company has established anti-skid test benches with two different states [4], static and dynamic. Among them, the static WSP anti-skid test bench uses the hardware based on the simulation model to calculate the wheel-rail adhesion, which is authorized by DIN EN ISO/IEC17025 and meets the requirements of the latest BSEN15595 and UIC54105 standards. Zhou et al. [4] from the Institute of Locomotive and Rolling Stock of China Academy of Railway Sciences also established a modular anti-skid simulation test platform. Based on dSPACE real-time simulator, Yangjun and Jinjun [5] built a semi physical simulation test bench for EMU braking anti-skid system, and compared the bench simulation results with the line test results to verify the effectiveness of the bench test. In order to test the control effect of anti-skid strategy written in EBCU, this paper designs a hardware-inthe-loop test bench based on the co-simulation model of LabView and AMESim. The test bench can provide test environment for EBCU product testing and anti-skid strategy research. 
In this paper, the hardware-in-the-loop test bench is mainly composed of an industrial computer, data acquisition circuit, and Bogie-controlled EBCU (excluding the pneumatic valve unit). The industrial control computer is used to provide a virtual train vehicle, a virtual train running environment, a virtual electric brake unit, and a virtual pneumatic valve unit. In the form of s Hardware-in-the-loop test bench, the test and research of train braking and anti-skid system performance are realized.

\section{OVERVIEW OF THE TEST BENCH}

The hardware of this test bench is mainly composed of a host computer and the braking system of two vehicles, as shown in Fig. 1. The composition of the host computer mainly includes an industrial computer, data acquisition card, signal conversion board (if necessary), MVB card, power supply circuit, etc. The entire hardware-in-the-loop simulation test platform also includes the actual braking system of two vehicles. The braking system of each vehicle includes two Bogie-controlled devices (that is, there are four Bogie-controlled braking devices in total). The braking devices are intended to communicate via the CAN bus (intranet) between the braking systems, and the braking devices communicate with the test bench via the MVB bus (external network).

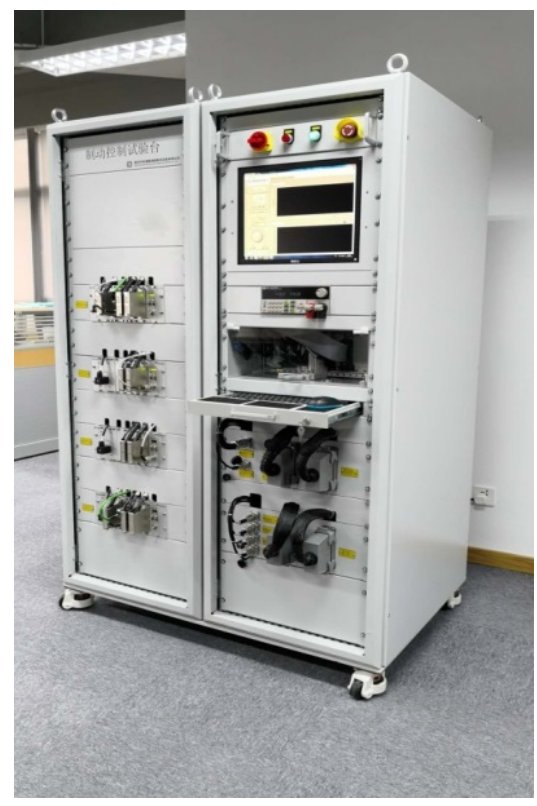

Figure 1: Hardware-in-the-loop simulation test bench.

\section{HARDWARE DESIGN OF TEST BENCH}

The hardware part of the test bench is composed of industrial computer (industrial controller and case), EBCU physical objects, data acquisition device, network communication device, keyboard and mouse, etc. The test bench is based on NI-PXI platform, data acquisition circuit, speed generating device and bogie-controlled braking devices of a motor vehicle and a trailer (excluding pneumatic valve unit). The NI-PXI platform ensures the synchronization of data acquisition, and uses the PXI system to provide virtual train vehicles, virtual train operating environments, virtual electric braking units, and virtual pneumatic valve units. 


\subsection{Design of measurement and control system}

PXI is a PC based on stable platform for measurement and automation systems. PXI is packaged in a stable, modular CompactPCI Eurocard, which improves the speed and performance of the PCI bus and integrates advanced timing and synchronization functions. Through the PXI system, you can realize all the characteristics of computer-based systems, and can achieve unparalleled integration in a mechanical box for industrial environments. According to the requirements, the components of the PXI system constructed by this test bench are as follows (Table 1).

Table 1: System components.

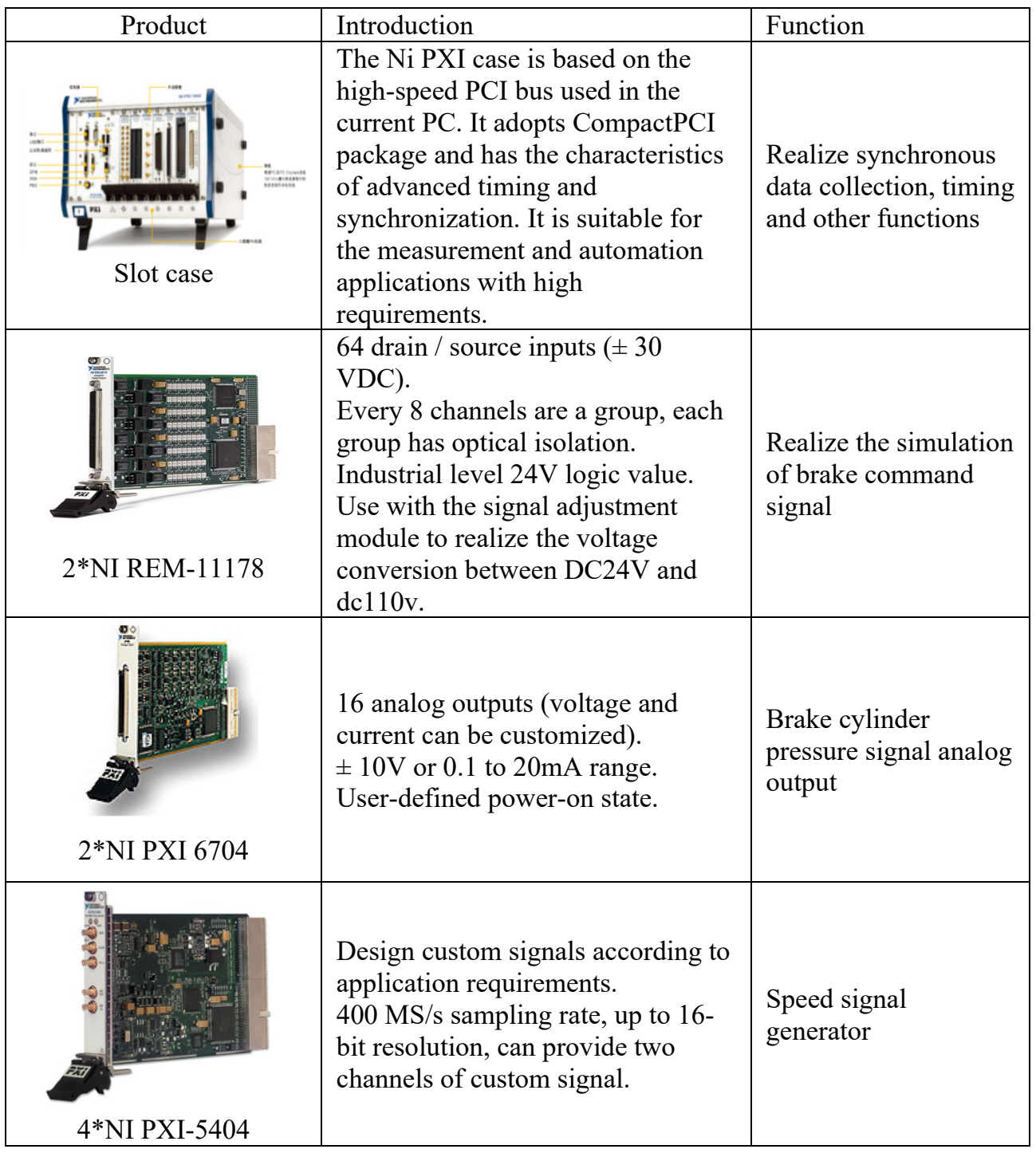


The test bench transmits signals through the NI-PXI system and MVB communication card. The NI-PXI system sends commands to the braking control device, and can monitor the data of the entire network in real time.

\section{SOFTWARE DESIGN OF TEST BENCH}

\subsection{Overall structure}

Fig. 2 shows the topology of the HIL test bench. The entire simulation software exchanges data with the external EBCU hardware through the data acquisition circuit and MVB network. The simulation software is divided into operation interface, train system model, TCU model and pneumatic valve model. Among them, the operation interface, the train system model and TCU model are built with LabVIEW software, and the pneumatic valve model is built with AMESim

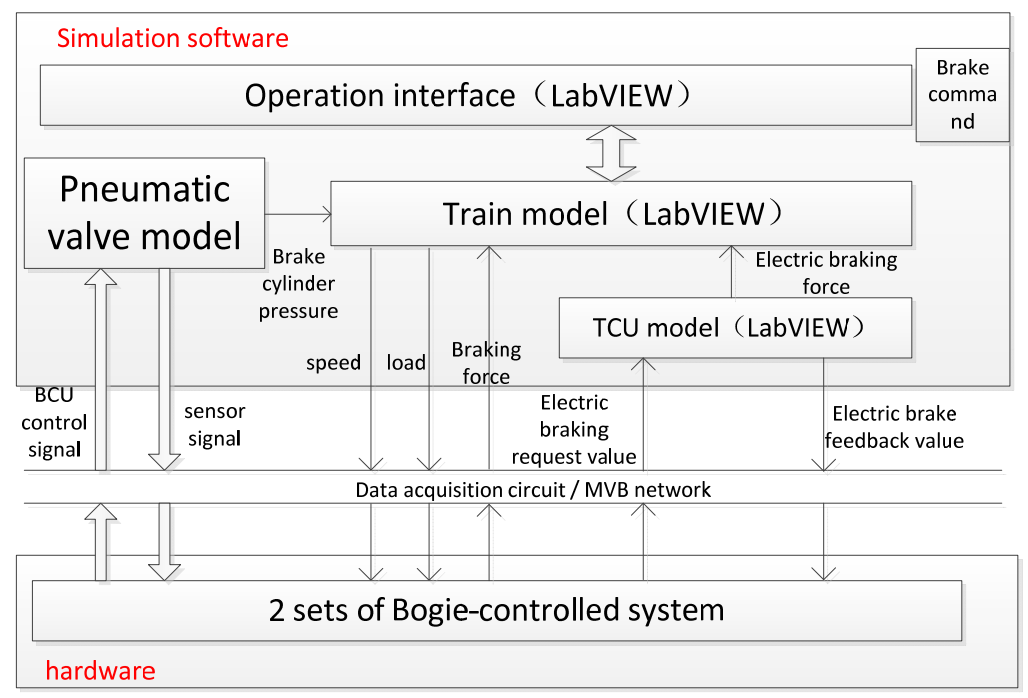

Figure 2: Topology diagram of HIL test bench.

In the actual line, the train has three degrees of freedom in longitudinal, vertical and horizontal directions. But in the braking process, we do not pay much attention to the vertical and lateral comfort indicators of the train. Without considering the curve conditions, the performance of the train braking conditions is mainly related to the longitudinal freedom of the vehicle. Because the longitudinal degree of the train is less coupled with the horizontal and vertical degrees. Therefore, the simplified establishment of the vehicle dynamics model only considers its longitudinal degree of freedom. The following is the dynamic equation description of each sub module.

\subsection{Vehicle dynamics model}

In the actual line, the train has three degrees of freedom in longitudinal, vertical and horizontal directions. But in the braking process, we do not pay much attention to the vertical and lateral comfort indicators of the train. Without considering the curve conditions, the 
performance of the train braking conditions is mainly related to the longitudinal freedom of the vehicle. Because the longitudinal degree of the train is less coupled with the horizontal and vertical degrees. Therefore, the simplified establishment of the vehicle dynamics model only considers its longitudinal degree of freedom. The following is the dynamic equation description of each sub module.

\subsubsection{Wheelset}

The motion state of wheelset includes rotation and longitudinal translation. In the rotating state, the force on wheel is mainly the friction of the brake shoe and the adhesion of the track to the single wheel; in the translational state, the force is primary suspension force and the adhesion force. Eqns (1) and (2) are the dynamic equations in the two states respectively

$$
\begin{gathered}
I_{w} \cdot \ddot{\theta}=K \cdot \varphi_{K} \cdot R_{w}-F_{b w} \cdot R_{w}, \\
M_{w} \cdot \ddot{x_{w}}=F_{f w}-F_{b w},
\end{gathered}
$$

where $M_{w}$ is the mass of single wheel, $I_{w}$ is the moment of inertia of wheel, $R_{w}$ is the radius of wheel, $\theta$ is the rotation angle of wheel, $\mathrm{K}$ is the equivalent clamping force, $\mathrm{F}_{\mathrm{bw}}$ is the longitudinal force of track on single wheel, $\mathrm{F}_{\mathrm{fw}}$ is the force of primary suspension on single wheel, $\varphi_{\mathrm{K}}$ is the friction coefficient of brake shoe.

\subsubsection{Bogie}

The longitudinal freedom of the bogie is mainly constrained by the forces of the primary suspension and secondary suspension. The number of primary suspension is four, and the number of secondary suspension is two. The force on the bogie is shown in eqn (3)

$$
\mathrm{M}_{\mathrm{f}} \cdot \ddot{\mathrm{x}}_{\mathrm{f}}=4 * \mathrm{~F}_{\mathrm{wf}}+2 * \mathrm{~F}_{\mathrm{cf}},
$$

where $\mathrm{M}_{\mathrm{f}}$ is the mass of the bogie, $\mathrm{x}_{\mathrm{f}}$ is the longitudinal displacement of the bogie, $\mathrm{F}_{\mathrm{wf}}$ is the force of the single primary suspension on the bogie, and $\mathrm{F}_{\mathrm{cf}}$ is the force of the single secondary suspension on the bogie.

\subsubsection{Vehicle body}

The longitudinal degree of freedom of the vehicle body is mainly affected by the secondary suspension force and coupler force. The number of secondary suspension force is four. The force on the bogie is shown in eqn (4)

$$
\mathrm{M}_{\mathrm{c}} \cdot \ddot{\mathrm{x}}_{\mathrm{c}}=4 * \mathrm{~F}_{\mathrm{fc}}+\mathrm{F}_{\text {coupler1 }}-\mathrm{F}_{\text {coupler2 }}-\mathrm{F}_{\text {resistance }},
$$

where $\mathrm{M}_{\mathrm{c}}$ is the mass of the vehicle body, $\mathrm{x}_{c}$ is the longitudinal displacement of the vehicle body, $\mathrm{F}_{\text {coupler1 }}$ and $\mathrm{F}_{\text {coupler2 }}$ are the coupling forces at both ends, and $\mathrm{F}_{\text {resistance }}$ is the basic resistance.

\subsubsection{Primary suspension, secondary suspension, coupler force}

In this system, the primary, secondary suspensions and coupler forces are simplified into spring damping mechanical models, and the formulas are shown in eqns (5)-(7)

$$
\begin{gathered}
\mathrm{F}_{\mathrm{fw}}=\mathrm{K}_{1 \mathrm{x}} \cdot\left(\mathrm{x}_{\mathrm{f}}-\mathrm{x}_{\mathrm{w}}\right)+\mathrm{C}_{1 \mathrm{x}} \cdot\left(\dot{\mathrm{x}}_{\mathrm{f}}-\mathrm{x}_{\mathrm{w}}\right), \\
\mathrm{F}_{\mathrm{cf}}=\mathrm{K}_{2 \mathrm{x}} \cdot\left(\mathrm{x}_{\mathrm{c}}-\mathrm{x}_{\mathrm{f}}\right)+\mathrm{C}_{2 \mathrm{x}} \cdot\left(\dot{\mathrm{x}}_{\mathrm{c}}-\dot{\mathrm{x}}_{\mathrm{f}}\right), \\
\mathrm{F}_{\text {coupler }}=\mathrm{K}_{\mathrm{c}} \cdot\left(\mathrm{x}_{\mathrm{c} 1}-\mathrm{x}_{\mathrm{c} 2}\right)+\mathrm{C}_{\mathrm{c}} \cdot\left(\mathrm{x}_{\mathrm{c} 1}-\mathrm{x}_{\mathrm{c} 2}\right),
\end{gathered}
$$


where $\mathrm{K}_{1 \mathrm{x}}$ is the longitudinal positioning stiffness between the single wheel and the bogie, $\mathrm{C}_{1 \mathrm{x}}$ is the longitudinal damping between the single wheel and the bogie, $\mathrm{K}_{2 \mathrm{x}}$ is the longitudinal positioning stiffness between the single wheel and the bogie, $C_{2 x}$ is the longitudinal damping between the single wheel and the bogie, $\mathrm{K}_{\mathrm{c}}$ is the longitudinal positioning stiffness between the vehicles and $\mathrm{C}_{\mathrm{c}}$ Longitudinal damping between vehicles.

\subsection{Wheel-rail adhesion model}

It is very important for the hardware in the loop test bench to establish the wheel rail adhesion model accurately. In this paper, the adhesion model proposed by Polach in 1999 is used as the simulation model [6]. The model can reflect the relationship between adhesion coefficient and axle load, vehicle speed, slip ratio, and can be applied to the calculation of adhesion coefficient under the sliding condition

$$
\mu=\frac{2 f_{0}\left[(1-A) e^{-B w}+A\right]}{\pi}\left[\frac{\frac{2 C \pi a^{2} b}{3 Q \mu} s}{1+\left(\frac{2 C \pi a^{2} b}{3 Q \mu} s\right)}+\arctan \left(\frac{2 C \pi a^{2} b}{3 Q \mu} s\right)\right],
$$

where $\mu$ is the adhesion coefficient; $f_{0}$ is the maximum friction coefficient of wheel rail; $\mathrm{Q}$ is the axle weight; A,B is the friction coefficient adjustment parameter; $w$ is the relative sliding speed; a is the length of the longitudinal half axis of the wheel rail elliptical contact area; $b$ is the length of the transverse half axis of the wheel rail elliptical contact area; $\mathrm{C}$ is the wheel rail contact shear stiffness; $s$ is the slip ratio.

According to the calculation formula of adhesion model, the three-dimensional surfaces of adhesion coefficient, velocity and slip ratio are drawn. As shown in Fig. 3, it can be seen that the relationship between adhesion coefficient and slip ratio increases first and then decreases, while the relationship between adhesion coefficient and velocity decreases with the increase of velocity. In addition, the slip ratio corresponding to the peak point of adhesion coefficient is set between $5 \%$ and $20 \%$ at different speeds, which is consistent with the wheel rail adhesion law measured by the International Railway Union (UIC) Research and Test Bureau (ore) [7].

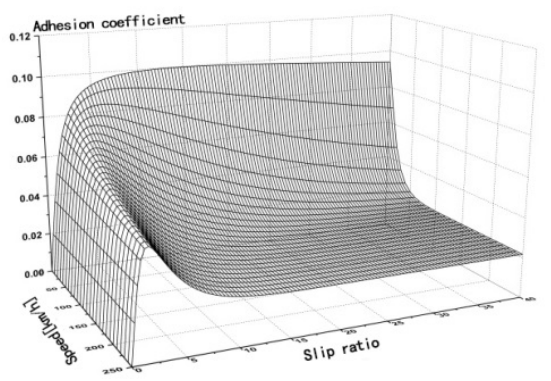

Figure 3: Three-dimensional surface of adhesion coefficient, vehicle speed and slip ratio.

\subsection{Brake system model}

The model of pneumatic valve unit is based on EP2002 and realized by AMESim. The pneumatic valve of bogie-controlled braking system is as follows in Fig. 4. The model 


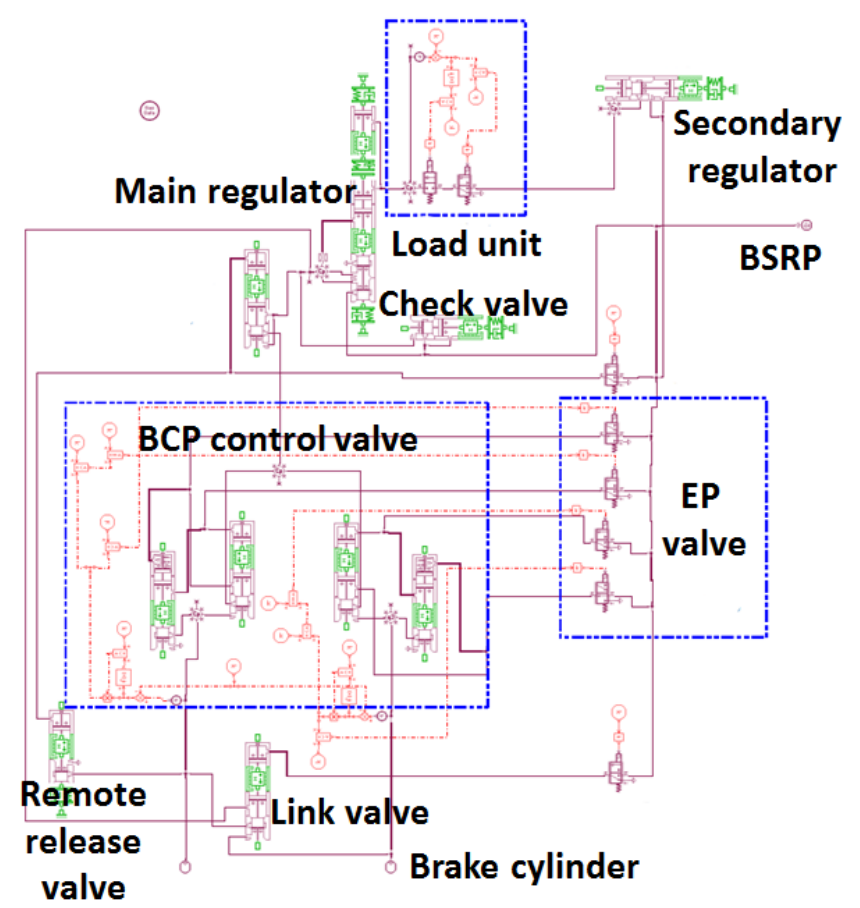

Figure 4: Pneumatic valve model.

includes the main regulator, secondary regulator, load unit, EP valve, BCP control valve, remote release valve, link valve and other components, which can fully simulate the function of the pneumatic part of the EP2002 system.

In order to realize the data exchange between different software, the method of cosimulation between LabVIEW and AMESim is adopted, and the simulation module mode is selected in AMESim.

\section{VALIDATION OF TEST BENCH}

According to the requirements of the anti-skid simulation device in EN 15595: 2011-07 Rail Applications-Braking-Wheel Slide Protection [8], it is necessary to adjust the adhesion model parameters to reproduce the actual vehicle line sliding test conditions on the bench. Through the comparison between the bench test data and the real vehicle test data, the accuracy and effectiveness of the bench are verified.

\subsection{Verification method}

The verification of bench shall be conducted under the adhesion conditions of dry rail and wet rail. The following are the test contents and requirements:

\subsubsection{Dry rail test}

The dry rail test simulates the adhesion condition of wheel rail with high adhesion when the vehicle does not slide under normal braking. The speed, deceleration and braking distance obtained from the bench simulation test are compared with the data obtained from the real 
vehicle test. The requirements of the test under dry rail are: the error between the simulated braking distance under different initial speeds and the theoretical braking distance calculated according to the target deceleration shall not exceed $5 \%$.

\subsubsection{Low adhesion test of wet rail}

According to EN15595 standards, the test data under wet rail condition should be compared with the actual vehicle test data. The comparison items include: braking distance, speed profile and amount of sliding.

(1) Braking distance

The performance requirements for braking distance of anti-skid simulation device in EN15595 standards are as follows: To verify the stopping distance simulation the error between simulation and reality shall be less than a given quantity

$$
\frac{\left|S_{\text {real }}-S_{\text {sim }}\right|}{S_{\text {real }}} * 100 \%<5 \% \text {, }
$$

where $S_{\text {sim }}$ is the simulated braking distance; $S_{\text {real }}$ is the measured braking distance in actual line.

(2) Speed profile

The requirements of EN 15595 are: The speed profile of the real braking and the simulated one shall be compared beginning from the start of braking (driver request) to the speed of $15 \mathrm{~km} / \mathrm{h}$. For each point of the speed profile at the time the error between the real and simulated speed shall be less than that of the given quantity

$$
\left|v_{\text {real }}-v_{\text {sim }}\right|<3 \mathrm{~km} / \mathrm{h} \text {. }
$$

(3) Amount of sliding

Finally, the percentage of total braking time that the axles are in a determined amount of sliding shall be calculated

$$
s=\left|\frac{V_{\text {vehicle }}-V_{\text {axle }}}{V_{\text {vehicle }}}\right| * 100 \%,
$$

where $\mathrm{s}$ is the slip ratio; $V_{\text {vehicle }}$ is vehicle speed; $V_{\text {axle }}$ is the axle speed

$$
\mathrm{AS}_{(n)}=100 * \frac{\sum_{i=1}^{m} t_{i}}{T}
$$

where $m$ is number of intervals; $t_{i}$ is partial intervals; $n$ is the range of different slip ratio; $T$ is time between the start of braking and the point at which the vehicle reaches $15 \mathrm{~km} / \mathrm{h} ; \frac{\sum_{i=1}^{m} t_{i}}{T}$ is total time within interval $\mathrm{T}$ during which the wheelset is in one of the above mentioned sliding

$$
\begin{gathered}
\text { error }_{n-\text { axle }}=\frac{\left|A S_{\text {real }}-A s_{\text {sim }}\right|}{A S_{\text {real }}} * 100, \\
E=\frac{\sum_{n=1}^{\text {totalaxles }} \text { error }_{n-\text { axle }}}{\text { totalaxles }}<20 \%,
\end{gathered}
$$

where error $_{n-a x l e}$ is the error between the real and the simulated amount of sliding for each axle. $E$ is the limits for the validation of the amount for sliding for each of the intervals. 


\subsection{Verification results}

\subsubsection{Dry rail test}

Fig. 6 shows the simulation results of the main rail at $300 \mathrm{~km} / \mathrm{h}$. As shown in Fig. 5, it can be seen that the hardware in the loop test bench can realize the normal braking function, and the actual deceleration can track the target deceleration accurately. The simulation of other different speeds is shown in Table 2. Under different speed levels and different brake modes, the error between the simulated braking distance and the theoretical braking distance is less than $5 \%$.
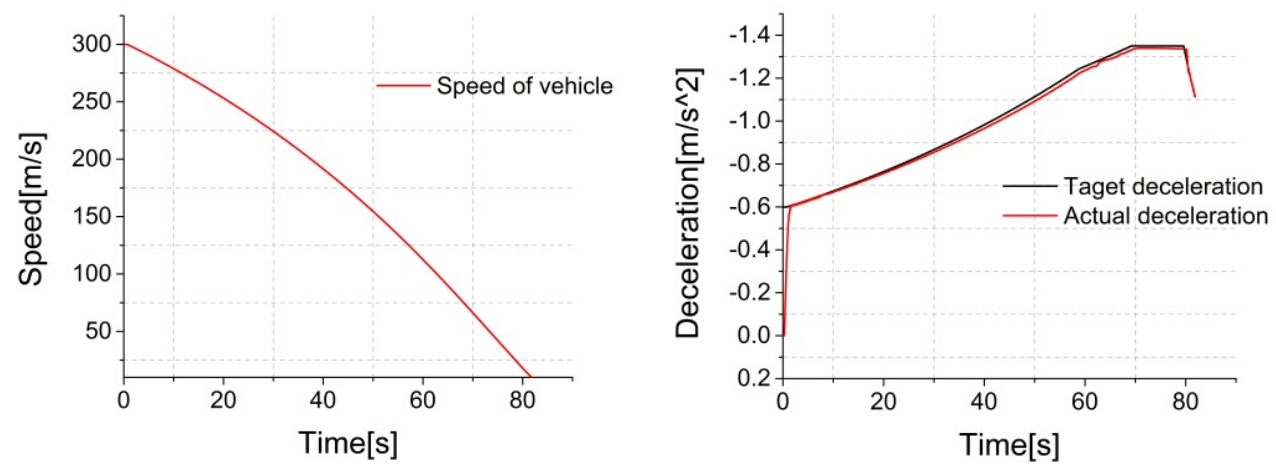

Figure 5: Speed and deceleration curve of dry rail condition.

Table 2: Results under dry rail condition.

\begin{tabular}{|c|c|c|c|c|c|}
\hline No & Brake mode & $\begin{array}{l}\text { Initial speed } \\
(\mathrm{km} / \mathrm{h})\end{array}$ & $\begin{array}{c}\text { Simulated } \\
\text { braking } \\
\text { distance }(\mathrm{m})\end{array}$ & $\begin{array}{c}\text { Theoretical } \\
\text { braking } \\
\text { distance }(\mathrm{m})\end{array}$ & Error $(\%)$ \\
\hline 1 & \multirow{3}{*}{$\begin{array}{l}\text { Maximum } \\
\text { service brake }\end{array}$} & 100 & 550.51 & 542.463 & 1.48 \\
\hline 2 & & 200 & $2,612.66$ & $2,603.54$ & 0.35 \\
\hline 3 & & 300 & $7,072.84$ & $7,139.20$ & 0.93 \\
\hline 4 & \multirow{3}{*}{ Fast brake } & 100 & 314.33 & 301.52 & 4.25 \\
\hline 5 & & 200 & $1,403.87$ & $1,367.57$ & 2.65 \\
\hline 6 & & 300 & $4,015.98$ & $3,951.21$ & 1.64 \\
\hline 7 & \multirow{3}{*}{$\begin{array}{c}\text { Emergency } \\
\text { brake }\end{array}$} & 100 & 412.66 & 399.70 & 3.24 \\
\hline 8 & & 200 & $1,619.55$ & $1,582.68$ & 2.33 \\
\hline 9 & & 300 & $4,078.72$ & $4,015.48$ & 1.58 \\
\hline
\end{tabular}

5.2.2 Low adhesion test of wet rail

The conditions of the selected actual line test data are as follows: the initial speed of the trailer is $150 \mathrm{~km} / \mathrm{h}$; the brake level is rapid braking; the rail surface is sprayed with antifreeze.

By selecting appropriate vehicle parameters and virtual track model parameters, the process of actual line anti-skid test is repeated. The simulation results are compared with the actual line test results according to the above three requirements. Because the actual line test data is only trailer data, the simulation also uses trailer for comparison. 
(1) Verification of braking distance

The comparison results of braking distance between actual line test value and simulation value are shown in Fig. 6 . The test value of braking distance of trailer is $891.4635 \mathrm{~m}$, the simulation value of braking distance of trailer is $883.2598 \mathrm{~m}$; the error is $0.93 \%$, which meets the relevant requirements of EN15595 for braking distance.

(2) Verification of speed profile

The comparison results of the speed test value and the simulation value of vehicle are shown in Fig. 7. At the same time, the maximum difference between simulation speed and test speed of vehicle is $2.62 \mathrm{~km} / \mathrm{h}$, which conforms to the relevant requirements of EN 15595 standards for speed profile.

(3) Verification of amount of sliding

The test condition is that the initial braking speed is $150 \mathrm{~km} / \mathrm{h}$, the braking mode is fast brake, and the rail surface is sprayed with antifreeze. The comparison between the simulation results of each axle speed and the results of actual line test is shown in Fig. 8.

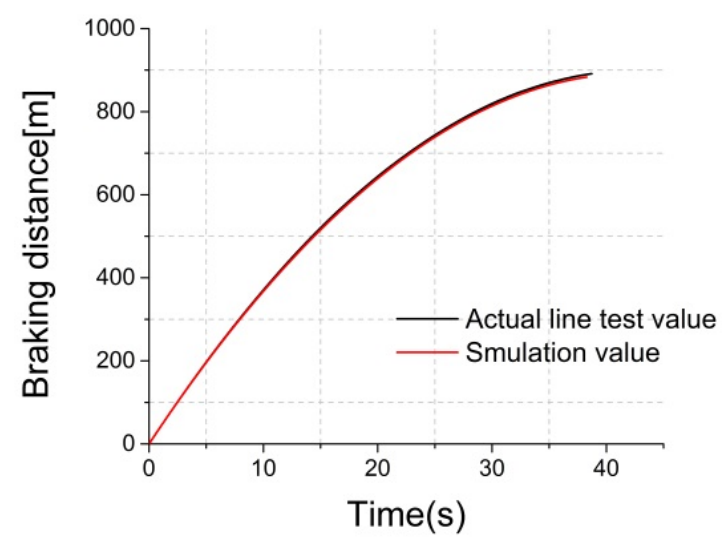

Figure 6: Comparison of braking distance.

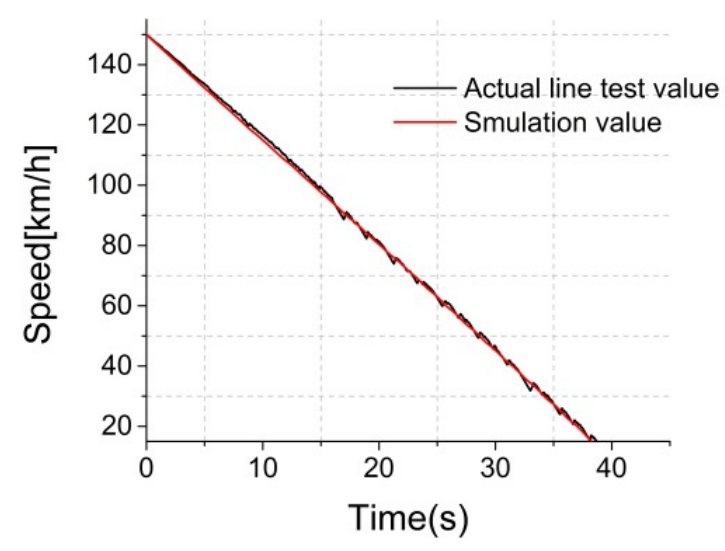

Figure 7: Comparison of speed profile. 


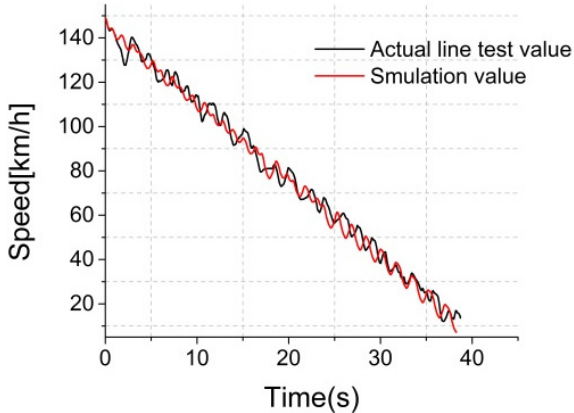

(a)

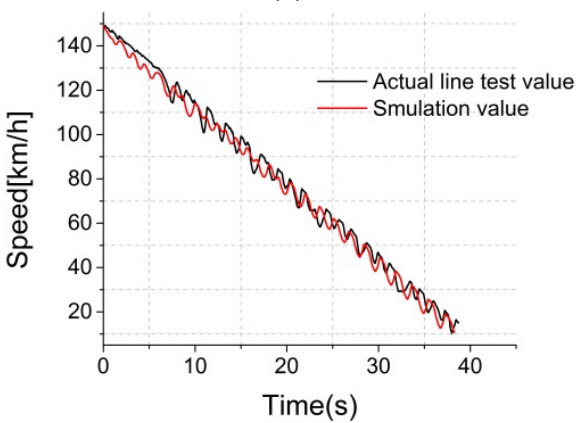

(c)

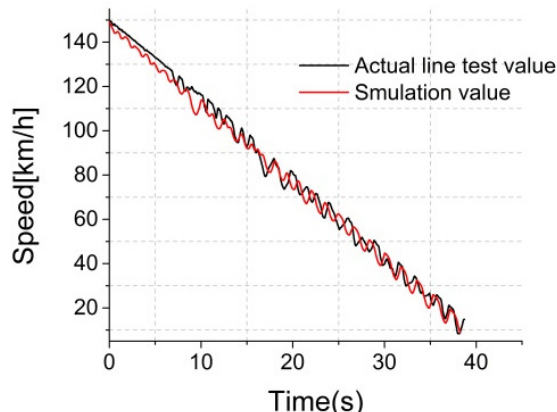

(b)

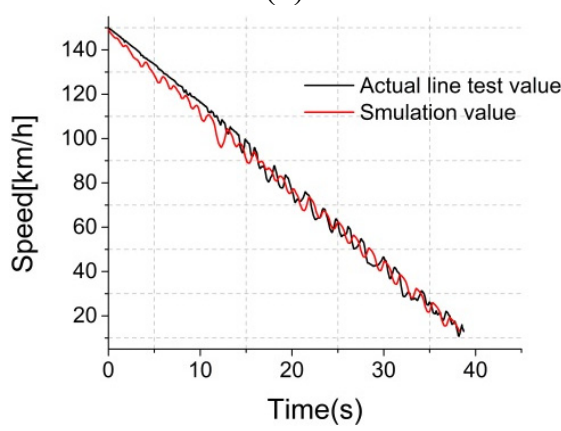

(d)

Figure 8: Comparison of axle speeds. (a) Trailer axle speed curve-axle 1; (b) Trailer axle speed curve-axle 2; (c) Trailer axle speed curve-axle 3; and (d) Trailer axle speed curve-axle 4.

According to the statistics of real line test data and simulation data, the simulation value and test value of time proportion of different slip ratio intervals of each axle are calculated, as shown in Tables 3 and 4 . It can be seen in Table 5 that the average error of time proportion of each slip ratio interval is basically less than $20 \%$, and the simulation performance meets the requirements.

Table 3: Actual line test value.

\begin{tabular}{|c|c|c|c|c|c|c|}
\hline $\begin{array}{c}\text { Slip } \\
\text { ratio }\end{array}$ & $0-5 \%$ & $5-10 \%$ & $10-20 \%$ & $20-30 \%$ & $30-40 \%$ & $>50 \%$ \\
\hline Axle 1 & 48.19215 & 30.68182 & 16.68388 & 0.955579 & 0.748967 & 0 \\
\hline Axle 2 & 58.80682 & 20.29959 & 13.06818 & 1.60124 & 0.516529 & 0 \\
\hline Axle 3 & 59.73657 & 20.06715 & 9.73657 & 2.169421 & 0.413223 & 0 \\
\hline Axle 4 & 46.79752 & 17.17459 & 17.82025 & 1.317149 & 0.335744 & 0 \\
\hline
\end{tabular}


Table 4: Simulation value.

\begin{tabular}{|c|c|c|c|c|c|c|}
\hline $\begin{array}{r}\text { Slip } \\
\text { ratio } \\
\text { No. }\end{array}$ & $0-5 \%$ & $5-10 \%$ & $10-20 \%$ & $20-30 \%$ & $30-40 \%$ & $>50 \%$ \\
\hline Axle 1 & 53.6632 & 25.49568 & 17.75194 & 1.457167 & 0.619602 & 0 \\
\hline Axle 1 & 62.49265 & 23.63117 & 11.31843 & 1.704922 & 0.724093 & 0 \\
\hline Axle 1 & 61.10815 & 23.46545 & 12.62906 & 2.257987 & 0.436744 & 0 \\
\hline Axle 1 & 63.89269 & 19.67033 & 14.1617 & 1.472668 & 0.292612 & 0 \\
\hline
\end{tabular}

Table 5: Error statistics.

\begin{tabular}{|l|c|c|c|c|c|c|}
\hline Slip ratio & $0-5 \%$ & $5-10 \%$ & $10-20 \%$ & $20-30 \%$ & $30-40 \%$ & $>50 \%$ \\
\hline Error of axle 1 (\%) & 11.35258 & 16.90298 & 6.401718 & 52.49053 & 17.27239 & 0 \\
\hline Error of axle 2 (\%) & 6.267689 & 16.41207 & 13.38937 & 6.475098 & 40.18438 & 0 \\
\hline Error of axle 3 (\%) & 2.296043 & 16.93466 & 29.70744 & 4.082448 & 5.692067 & 0 \\
\hline Error of axle 4 (\%) & 36.53007 & 14.53162 & 20.53029 & 11.80726 & 12.84656 & 0 \\
\hline
\end{tabular}

\section{CONCLUSION}

1. The hardware in the loop test-bed is built. LabVIEW and AMESim are used to provide virtual train vehicle, virtual train operation environment, virtual electric braking unit and virtual pneumatic valve unit. Data exchange with EBCU is realized by MVB bus and data acquisition cards.

2. According to EN15595 standards, by comparing the actual line test data and simulation data, it is proved that the hardware-in-the-loop test bench can carry out the simulation test of braking and anti-skid system to a certain extent.

\section{ACKNOWLEDGEMENTS}

Thank you for the experimental equipment provided by Nanjing Haitai Brake Equipment Co. Ltd. In addition, we are especially grateful to the foundation (U1534205) for its financial support.

\section{REFERENCES}

[1] Pugi, L., Malvezzi, M., Tarasconi, A., Palazzolo, A., Cocci, G. \& Violani, M., HIL simulation of WSP systems on Mi-6 test rig. Vehicle System Dynamics, 44, pp. 18431852, 2006.

[2] Conti, R. et al., An innovative hardware in the loop architecture for the analysis of railway braking under degraded adhesion conditions through roller-rigs. Mechatronics, 2014.

[3] Allotta, B. et al., Development of an innovative wheel-rail contact model for the analysis of degraded adhesion in railway systems. Tribology International, 69, pp. 128-140, 2014.

[4] Zhou, J., Hongfa, C., Wei, C. \& Heping, L., Research on the standard and method of simulation bench test for high speed train anti-skid system [J]. Railway Rolling Stock, 33(2), pp. 43-50, 2013. (In Chinese.)

[5] Yangjun, L.Y. \& Jinjun, L., Research on hardware in the loop simulation test of EMU antiskid system, 5, pp. 102-107, 2018. (In Chinese.) 
[6] Polach, O., A fast wheel-rail forces calculation computer code. Vehicle Syst. Dyn., 33, pp. 728-739, 1999.

[7] ORE/UIC, Synthesis report: The current state of knowledge about wheel-rail adhesion. UIC B44 RP14-1978[S].

[8] Railway applications-Braking-Wheel slide protection (includes Amendment A1:2011), English translation of DIN EN 15595:2011-07. 